\title{
Solvation and reactivity of inorganic complexes
}

\author{
John Burgess \\ Department of Chemistry, University of Leicester, Leicester LE1 7RH, U.K.
}

\begin{abstract}
There is a great diversity of medium effects on reactivity for inorganic reactions; observed patterns have been considered in relation to a number of intrinsic properties and empirical parameters. The present review concentrates on metal complex formation and on electron transfer reactions, both inner- and outer-sphere. Solvent and "organised medium" (micelles; microemulsions) effects are described and discussed.
\end{abstract}

\section{INTRODUCTION}

The aims of this contribution are to give some idea of the range and variety of inorganic systems for which kinetic parameters have been reported in various solvent media, and to give some indication of the role of solvents and solvation in determining reactivity trends. Solute-solvent, solvent-solvent, and solute-solute interactions will all be considered, in various guises depending on the reaction involved. Time and space restrictions dictate that only a small selection of systems can be mentioned here; a number of other systems are treated at a similar level elsewhere (ref. 1). For much more extensive coverage, and some physical, organic, and historical background to the area, the reader is referred to a recently completed review entitled "Solvent and Microdomain Effects in Inorganic Chemistry" (ref. 2).

\section{MEDIUM EFFECTS ON REACTIVITY}

The study of medium effects on inorganic kinetics started several decades after such studies in organic chemistry - Berthelot and Péan de Saint-Gilles (ref. 3) were probably the first, in 1862, to describe solvent effects on reactivity, for esterification of ethanol by acetic acid; Menschutkin published the first detailed account of solvent effects on reactivity, for the reaction which bears his name, in 1890 (ref. 4). In view of this historical precedence, the first examples of the very large effects which change of solvent medium can have on reactivity will be taken from organic chemistry. Thus for the familiar reaction of t-butyl chloride solvolysis, rate constants decrease by around a million times on going from water as solvent to t-butyl alcohol (ref. 5). On the other hand, the [4+2] cycloaddition of nitrosobenzene to 1,3-cyclohexadiene has rate constants lying within the very small range of 0.010 to $0.015 \mathrm{dm}^{3} \mathrm{~mol}^{-1} \mathrm{~s}^{-1}$ (at $298.2 \mathrm{~K}$ ) in a selection of solvents as diverse as ethanol, hexane, and benzene (ref. 6). Inorganic chemistry can provide a comparable range, with dissociation of the $\left[\mathrm{Rh}\left\{\mathrm{P}(\mathrm{OMe})_{3}\right\}_{5}\right]^{+}$cation occurring with the same rate constant in five different solvents (ref. 7), but rate constants for peroxodisulphate oxidation of the ternary iron(II) complex $\left[\mathrm{Fe}(\mathrm{CN})_{2}(\mathrm{bipy})_{2}\right]$ decreasing even more markedly than those for t-butyl chloride solvolysis on going from water to methanol-water mixtures (ref. 8). 
Just as kinetic parameters for a given reaction may, or may not, change dramatically on going from water into binary aqueous mixtures or into non-aqueous solvents, so they may also change dramatically, significantly, or negligibly on transfer into micellar or microemulsion media (ref. 9). The classic inorganic example of enormous rate enhancement, again of the order of a million times, involves $\mathrm{Hg}^{2+}$-catalysed aquation of the chloro- and bromo-complexes $\left[\mathrm{Co}\left(\mathrm{NH}_{3}\right)_{5} \mathrm{X}\right]^{2+}$ in anionic micelles such and in polyelectrolytes (ref. 10$)$.

It is interesting to compare these solvent and micellar effects on reactivity with the effects of coordinating a metal ion to a substrate. The $10^{8}$-fold acceleration of hydrolysis of acetonitrile when coordinated to ruthenium(III) in $\left[\mathrm{Ru}\left(\mathrm{NH}_{3}\right)_{5}(\mathrm{MeCN})\right]^{3+}$ (ref. 11) is only a hundred times larger than the medium effects just described, while the $10^{3}$ to $10^{4}$ fold acceleration normally found for peptide or ester hydrolysis when coordinated to cobalt(III) in complexes of the $\left[\mathrm{Co}(e n)_{2}(L L)\right]^{3+}$ type (ref. 12) is modest by comparison with the more dramatic medium effects mentioned above.

Before getting into details of kinetic effects on reactivities one should mention the broader topic of the possibility of a change in mechanism. Again the first example will be organic - $t$-butyl chloride solvolysis gives $t$-butyl alcohol or butene, or a mixture of these two products, according to solvent (ref. 13). In inorganic or organometallic chemistry solvent control of products often arises from possibilities of ionic or solvento intermediates in polar or coordinating solvents which are not possible in apolar or non-coordinating media. Examples of the former include the reactions of $\left\{\mathrm{Fe}(\mathrm{cp})(\mathrm{CO})_{2}\right\}_{2}$ with iodine (ref. 14) or of $\mathrm{Mn}(\mathrm{cp})(\mathrm{CO})_{3}$ with alkenes (ref. 15), of the latter substitution at square-planar, e.g. platinum(II), complexes (ref. 16). In the limit the medium may force a change of reaction rather than just of mechanism or of reactivity. A simple example of this would be the solvolysis of $\left[\mathrm{Co}\left(\mathrm{NH}_{3}\right)_{5} \mathrm{Cl}\right]^{2+}$ in a range of coordinating solvents such as methanol or dimethyl sulphoxide; a more abstruse example is substitution at manganese pentacarbonyl halides, where the normal route of carbon monoxide replacement changes to one of halide replacement in water-rich solvent mixtures (ref. 17). Such possibilities have to be borne in mind when interpreting solvent effects on reactivity per se.

\section{PROPERTIES AND PARAMETERS}

A wide range of solvent properties, empirical parameters, and kinetic data have been pressed into service either to assist in using solvent effects on reactivities to diagnose mechanisms of reactions or to further understanding of the role of solvent and solvation on reactions of known mechanism. The four most commonly encountered intrinsic solvent properties here are dielectric constants, viscosities, enthalpies of vaporisation, and the somewhat more nebulous 'solvent structure'.

\section{Intrinsic solvent properties}

Dielectric functions are the most frequently used. The kinetic data are normally, but not always, rate constants; correlation may be attempted with the static dielectric constant (permittivity) $D, 1 / D, D^{3},(D-1) /(2 D+1)$, or the combination of static and optical dielectric functions $1 / n^{2}-1 / D$ ( $n=$ refractive index). The last mentioned is generally used in the context of electron transfer (see below). Dielectric correlations also frequently appear in connection with substitutional processes in view of the key role of dielectric constant in the Born equation. There is thus a direct link with developing solvation of a leaving group, e.g. a halide from a metal complex of the $\mathrm{ML}_{5} \mathrm{X}^{\mathrm{n}-}$ type. Wells has reviewed a large number of such correlations, demonstrating severe limitations on their applicability (ref. 18).

Viscosity is of obvious importance, especially in controlling the approach of reactants in fast bimolecular processes. It is also of importance in relation to the outer-sphere or 
solvational reorganisation associated with electron transfer processes, and may have an effect even in intramolecular processes such as racemisation and isomerisation.

Enthalpies of vaporisation are of particular relevance to dissociative processes, where, particularly in a hydrogen-bonded medium, considerable work may have to be done to expand the cavity occupied by the reactant to accommodate the larger volume of the developing transition state. There is an obvious close link here with concepts of solvent structure.

\section{Micelles and microemulsions}

Detailed descriptions of micelles, microemulsions, vesicles, and membranes, and their interrelations, will be found elsewhere (ref, 19), as will the proceedings of two recent meetings in which kinetic behaviour in organised media was discussed at some length in the context of properties and applications (refs. 20,21). Concentration effects are often paramount in determining reactivity in micelles, particularly when a cationic surfactant is used to catalyse a reaction between two negatively charged reagents, or vice versa. However the role of solvation should not be ignored, especially for heavily hydrated ions, e.g. halides (ref. 22). Metal cations can have a fundamental effect on organisation, as illustrated by the demonstration that addition of $\mathrm{Cu}^{2+}$ to planar bilayers of the potential ligand dihexadecyl[5-(1-imidazolyl)-3-oxapentyl]methylammonium chloride causes a change of organisation to closed vesicles (ref. 23).

\section{Empirical solvent parameters}

A selection of these appear in Table 1 (refs. 24-35), to give an idea of the range. Most concentrate on one aspect of the solvent, often spectroscopic, or provide kinetic correlations for a limited range of not too dissimilar reactions. Brownstein's $S$ parameter (ref. 35) is of particular interest in that it attempts, by incorporating several diverse terms, to reflect some sort of overall solvation propensity. Multiparameter equations such as those of Kamlet and Taft (ref. 36) or of Abbott and Rusling (ref. 37) provide examples of the alternative approach to trying to accommodate a selection of the diverse properties of solvents into equations of wide applicability.

TABLE 1. Empirical Solvent Parameters.

\begin{tabular}{|c|c|c|}
\hline Parame & Probe (proposers) & \\
\hline \multicolumn{3}{|c|}{ Kinetic } \\
\hline$Y$ & t-Butyl chloride solvolysis (Grunwald and winstein) & $(\operatorname{ref} .25)$ \\
\hline  & exo:endo in $\mathrm{Cp}+$ methyl acrylate tBerson, flamlet, and Muellet & (ref. 26) \\
\hline $\mathrm{x}$ & tetraalkyltin plus halogen (Gielen and Nasielski) & $(r \in(.27)$ \\
\hline \multicolumn{3}{|l|}{ Other } \\
\hline 乙 & Solvatochromism of 1-Et-4-methoxycarbonylpyridinium lodide & (ref. 28) \\
\hline$\varepsilon_{\mathbf{T}}$ & Solvatochromism of pyridinium N-phenolbetaines (Reichardt) & $(r \in f, 29)$ \\
\hline $\mathrm{DN}$ & Donor numbers; $\Delta \mathrm{H}$ for solvent+SbCl 5 in $\mathrm{CH}_{2} \mathrm{ClCH}_{2} \mathrm{Cl}$ (Gutmann) & $($ ref, 30) \\
\hline AN & Acceptor numbers; ${ }^{31} \mathrm{P}$ Chemical shifts (Gutmann and Mayer) & $(\operatorname{ref}, 31)$ \\
\hline 8 & Olelectric (Abboud and Taft) & $(r$ ef. 32$)$ \\
\hline$n^{*}$ & Solvent polarity and polarisability (Kamlet and Taft) & $($ ref. 33) \\
\hline$g(5)$ & Solubilities (Letellier and Gaborlaud) & $(\operatorname{ref} .34)$ \\
\hline $\mathbf{s}$ & Generalised solvent parameter (Brownstein) & $(r$ ef. 35) \\
\hline
\end{tabular}


Solvatochromic scales based thereon are important in relation to mixed solvents, and to micelles and other organised media, for they can act indicate the local solvation environment of a solute. Particularly interesting are the of ten water-soluble inorganic solvatochromic complexes such as pentacyanoferrates(II) $\left[\mathrm{Fe}(\mathrm{CN})_{5} \mathrm{~L}\right]^{\mathrm{n}-}$ and ternary complexes of the $\left.\left[\mathrm{Fe}(\mathrm{CN})_{2} \text { (diimine) }\right)_{2}\right]$ and $\left[\mathrm{Fe}(\mathrm{CN})_{4} \text { (diimine) }\right]^{2-}$ type (ref. 38). Solvatochromism and transfer chemical potentials (ref. 39) of such reactants are providing valuable information on initial state solvation in a range of substitution and redox reactions in binary aqueous and organised media (ref. 40).

\section{Kinetic parameters}

The activation entropy and volume for a reaction in solution may also provide vital evidence either in relation to the establishment of mechanism, or, for a reaction of known mechanism, in relation to the role of the solvent (see below). A combination of kinetic and thermodynamic information can permit the analysis of solvent effects on reactivity into initial state and transition state contributions. This approach was developed qualitatively by Hughes and Ingold in the 1930s (ref. 13), applied quantitatively firstly to organic reactions, and later extended to inorganic systems (refs. 41,42). As indicated below, this approach can prove informative for substitution, electron transfer, and other types of reaction.

\section{INORGANIC REACTIONS: GENERAL}

Solvent effects on the kinetics of intramolecular processes such as racemisation and isomerisation, and on a range of substitution reactions, have been discussed in earlier presentations in conferences in this series (ref. 42). In the present contribution attention will be focussed on electron transfer reactions, which were rather neglected earlier. These, and the linking topic of medium effects on kinetics of formation of metal complexes (the Eigen-Wilkins mechanism (ref. 43)), will be considered in the following sections.

\section{COMPLEX FORMATION}

The role of the solvent was brought out particularly clearly in Bennetto and Caldin's work on kinetics of solvent exchange at first row transition metal $2+$ ion and of their complex formation reactions with such ligands as 2,2'-bipyridyl (bipy) and pyridine 2-azo$4^{\prime}$-dimethyl-aniline (pada) (ref. 44). The relation between enthalpies of activation for such reactions and enthalpies of vaporisation (ref. 45) of the respective solvents is shown in Fig. 1 (ref. 44). There is also a convincing correlation between activation enthalpies and entropies for these reactions over a rather wide range of $\Delta H^{\neq}$and $\Delta S^{\neq}$(Fig. 2). Figures 1 and 2 refer to single solvents; in Fig. 3 the activation enthalpy vs. activation entropy plot is shown for formation of mono-2,2'-bipyridyl-nickel(II) in methanol - water mixtures. The remarkable shape of this plot can be rationalised fairly successfully in terms of solvent structural effects in this series of solvent mixtures. These $\Delta H^{\neq}$and $\Delta S^{\neq}$effects compensate to a considerable degree; they are, as one would expect, larger in, e.g., t-butyl alcohol. Conversely they are negligible in solvent mixtures where the structural effects characteristic of alcohol-water mixtures are not apparent. This is illustrated in Fig. 4, where benzyl chloride (ref. 46) is substrate, to emphasise that these phenomena are not peculiar to formation of inorganic complexes.

The solvent structural effects just invoked are considerably less than in such media as 1,2-ethanediol (glycol) or 1,2,3-propanetriol (glycerol). The enormous increases in viscosity on going from water to glycerol-rich media and to pure glycerol can force a change of mechanism. In water, rate constants for complex formation from cations such as $\mathrm{Mn}^{2+}, \mathrm{Co}^{2+}, \mathrm{Ni}^{2+}, \mathrm{Cu}^{2+}$, and $\mathrm{Zn}^{2+}$ span a range of approximately $10^{9}-$ fold. This range 


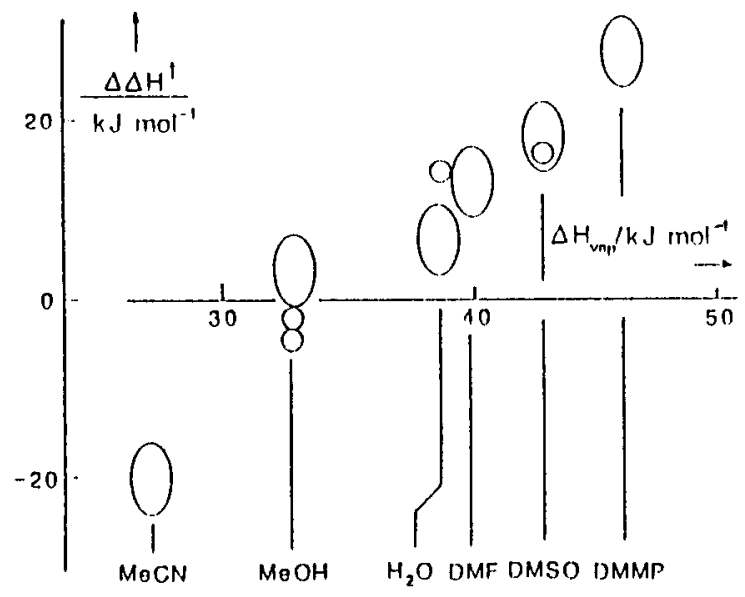

Fig. 1. Dependence of the relative enthalpies of substitution $\left(\mathrm{Ni}^{2+}, \mathrm{Co}^{2+}\right.$ plus bipy or terpy) and solvent exchange on enthalpy of vaporisation of the solvent (reproduced with the permission of the publishers, Pergamon Press, oxford).

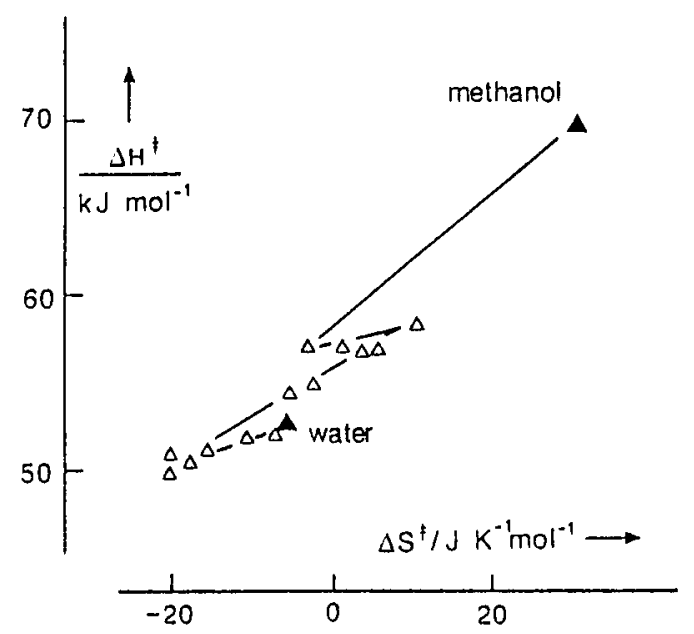

Fig. 3. Relation between activation enthalpies and entropies for reaction of $\mathrm{Ni}^{2+}$ with $2,2^{\prime}$-bipyridyl in methanol-water mixtures.

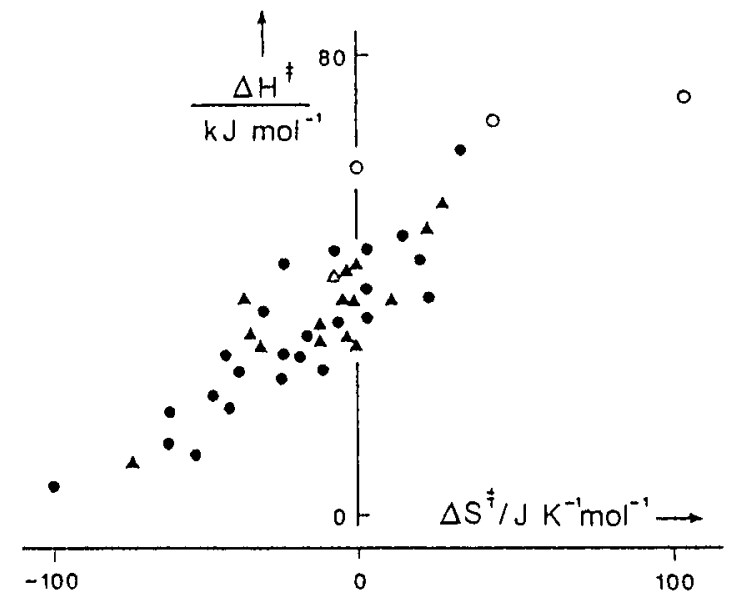

Fig. 2. Activation enthalpy/entropy correlation for substitution ( $\Delta \Delta$, by bipy or terpy) and for solvent exchange $(\bullet)$ at $\mathrm{M}^{2+}$ in water and

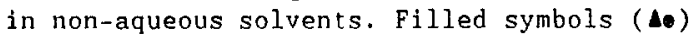
refer to transition metal cations, open symbols $(\Delta o)$ to sp-block cations ( $v i z . B e, M g$ ) (reproduced with the perinission of the publishers, Pergamon Press, 0xford).

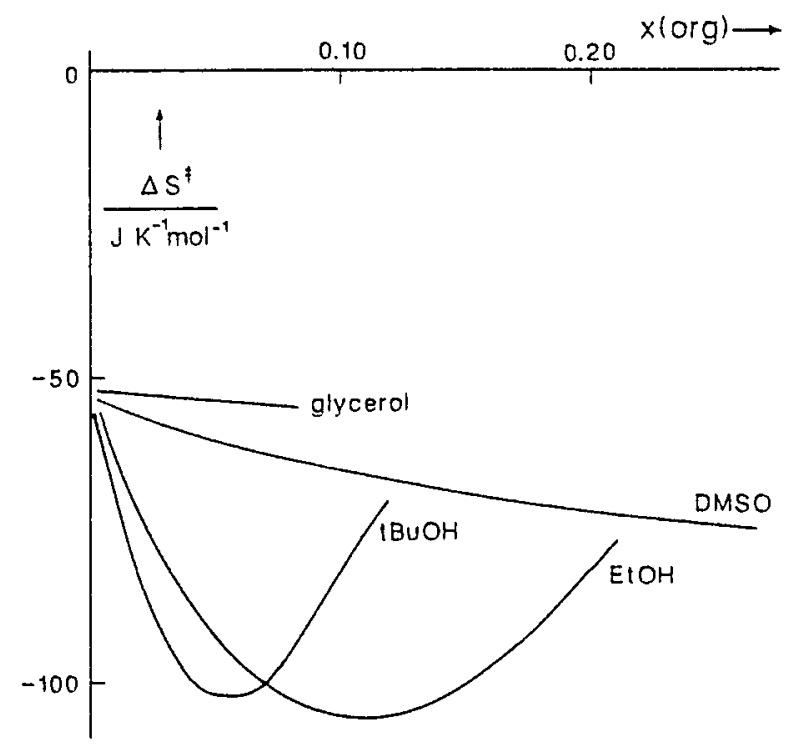

Fig. 4. Variation of activation entropy with solvent composition for solvolysis of benzyl chloride in binary aqueous solvent mixtures (reproduced with the permission of the publishers, Pergamon Press, Oxford). 


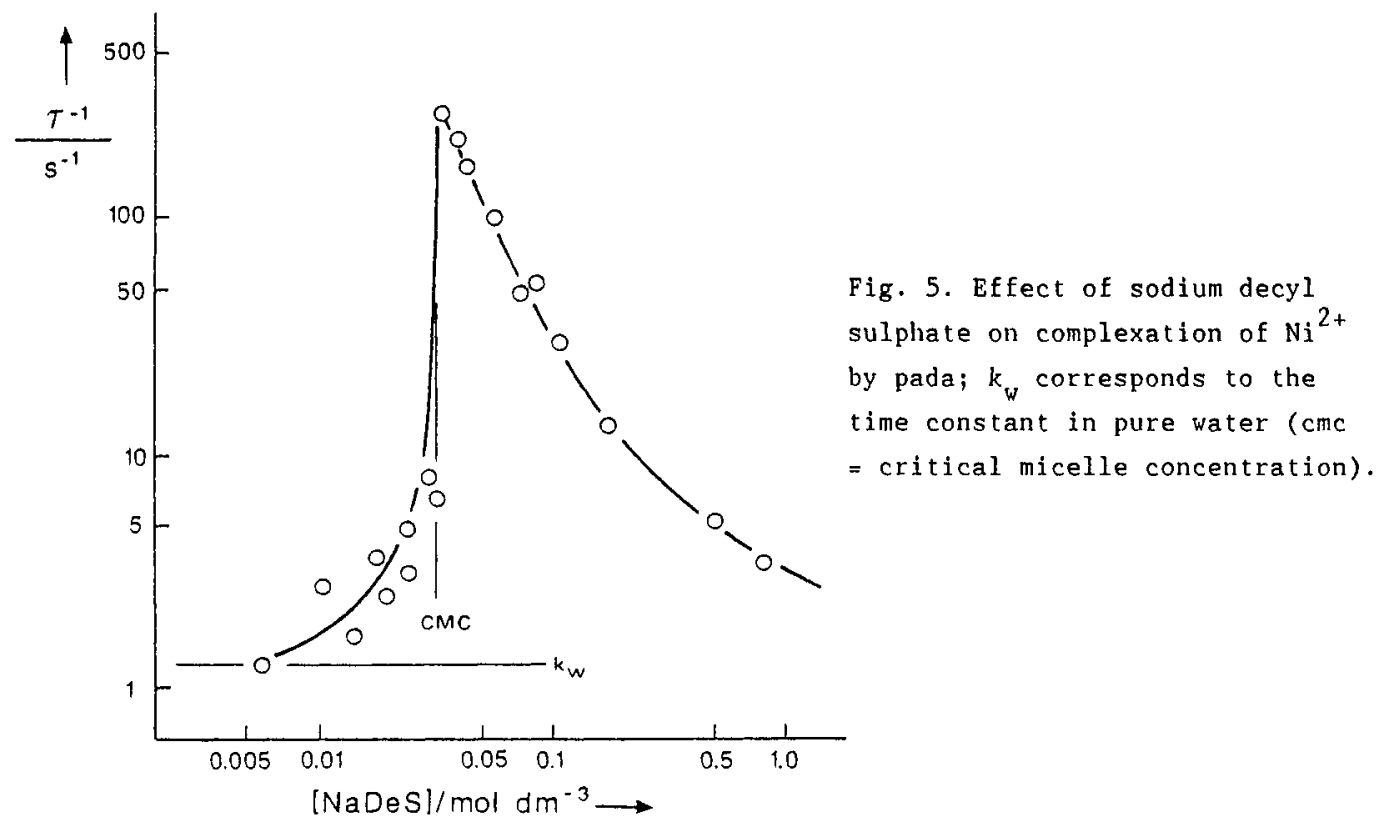

reflects the key role of Crystal Field effects (and Jahn-Teller for $\mathrm{Cu}^{2+}$ ). In glycerol the range is only 4-fold (ref. 47). Viscosity clearly dominates, but as rate constants are two orders of magnitude less than expected for diffusion control other factors must also be significant. A similar situation has been described for reactions of haemoglobin and for myoglobin with carbon monoxide (ref. 48).

Presumably all the features mentioned in the two preceding paragraphs stem from medium effects on the pre-association equilibrium rather than the interchange step in the Eigen-Wilkins complex formation mechanism (ref. 43). The same is true in general for these reactions in organised media, where maximum enhancement of reactivity results from the favourable bringing together of the reagents in the micelle, reversed micelle, or other aggregate. Simple electrostatic effects are not important here, since reactions of positively charged ligands with metal cations are very rare. What is more important is the hydrophilic or hydrophobic nature of the ligand, and its partitioning behaviour, and thus whether the reaction site is at the aggregate-water interface, in the bulk aqueous phase, or in water pools of reversed micelles (ref. 2). Kinetic consequences can be illustrated by, e.g., $\mathrm{Ni}^{2+}$ plus pada in sodium decylsulphate solutions. Figure 5 shows the dramatic enhancement of reactivity in the region of the critical micelle concentration (c.m.c.) (ref. 49). Kinetics of reaction of $\mathrm{Ni}^{2+}$ with 8-hydroxyquinoline and its 7-(4-ethyl-1methyloctyl) derivative, the extractant Kelex 100, have been monitored in a range of organised media. Whereas the reaction with 8 -hydroxyquinoline is essentially a bulk reaction, the much more lipophilic $\mathrm{C}_{11}$ derivative reacts in the interfacial region (ref. 50 ).

\section{ELECTRON TRANSFER: GENERAL}

Both the inner-sphere and outer-sphere mechanisms for electron transfer (ref. 51) are multistage processes - this is particularly true for the former. The two important stages in outer-sphere electron transfer are pre-association of the reactants and the subsequent actual electron transfer. In the inner-sphere mechanism pre-association is followed by ligand interchange to give the bridged binuclear transition state or intermediate in which the electron transfer takes place. For a readily reducible bridging ligand and a $t_{2 g} 6$ oxidant, such as cobalt(III), the electron transfer itself may take place in two distinct stages, the electron dwelling for a significant time on the bridging ligand (the so-called "chemical mechanism" (ref. 52)). The first two stages of the inner-sphere mechanism are 
identical with those for complex formation, and one may therefore expect medium effects to be very similar to those described for complex formation in the preceding section. The first stage, that of pre-association, is common to both electron transfer mechanisms and complex formation. As stated above, medium effects on such pre-equilibria are often very important, indeed often dominate medium effects on reactivity. This has been illustrated in the preceding section, and will be mentioned again in connection with outer-sphere electron transfer below.

\section{ELECTRON TRANSFER: INNER-SPHERE}

In practice it is quite difficult to observe separately the two main components of inner-sphere electron transfer, formation and subsequent electron transfer (ref. 53). In Taube's classic reaction (ref. 54), $\mathrm{Cr}^{2+}$ aq reduction of $\left[\mathrm{Co}\left(\mathrm{NH}_{3}\right)_{5} \mathrm{Cl}\right]^{2+}$, electron transfer through bridging chloride follows much too rapidly on the heels of the bridged intermediate to be kinetically distinguishable and thus to have its response to changes in medium assessed.

We have found that cobalt(III) oxidations of pentacyanoferrates(II) can be designed so that the kinetics both of complex formation and of the subsequent intramolecular electron transfer can be measured as a function of composition in binary aqueous solvent media. Toma (ref. 55) first reported the two stage kinetic pattern for reactions of the type

$$
\begin{aligned}
{\left[\mathrm{L}_{5} \mathrm{Co}(\mathrm{LL})\right]^{3+}+\left[\mathrm{Fe}(\mathrm{CN})_{5}\left(\mathrm{OH}_{2}\right)\right]^{3-} } & \rightarrow\left[\mathrm{L}_{5} \mathrm{Co}(\mu-\mathrm{LL}) \mathrm{Fe}(\mathrm{CN})_{5}\right] \\
& \rightarrow\left[\mathrm{Fe}(\mathrm{CN})_{5}(\mathrm{LL})\right]^{3-}+\mathrm{Co}^{2+}+5 \mathrm{~L},
\end{aligned}
$$

where $L_{5}$ represents an ammine or amine ligand set, and LL a potentially bidentate ligand such as pyrazine. Reactivities in the two stages can be adjusted through appropriate choice of $\mathrm{L}$ and $\mathrm{LL}$; best results on medium effects were obtained with $\left[\mathrm{Co}(\mathrm{pzc})\left(\mathrm{NH}_{3}\right)_{4}\right]^{2+}$ ( $\mathrm{pzc}=$ pyrazine carboxylate) as oxidant (ref. 56). It is noteworthy that the activation volume for intramolecular electron transfer in the analogue $\left[(\mathrm{en})_{2} \mathrm{Co}(\mathrm{pzc}) \mathrm{Fe}(\mathrm{CN})_{5}\right]^{-}$is +28 $\mathrm{cm}^{3} \mathrm{~mol}^{-1}$ in water (but only +7 in $60 \%$ methanol) under conditions of thermal activation, only $+3 \mathrm{~cm}^{3} \mathrm{~mol}^{-1}$ under photochemical activation (ref. 57). In the thermal case electron transfer takes place directly from the iron to the cobalt, and the observed $\Delta V^{\neq}$reflects released of electrostricted water from the pentacyanoferrate moiety as its negative charge decreases. This effect is also apparent in an initial state - transition state analysis of the rate constant trend in methanol-water mixtures (ref. 56). In the photochemical case the "chemical mechanism" operates, and the small $\Delta V^{\neq}$reflects the very modest change in solvation as the electron transfers not from the $\mathrm{Fe}(\mathrm{CN})_{5}{ }^{3-}$ moiety but just from the bridging pyrazine carboxylate to the cobalt (ref. 57).

The difficulty with assessing medium effects on reactivity in systems of the type just discussed is that the medium affects not only the kinetics but also the thermodynamic driving force for the reaction. It is well-nigh impossible to estimate the contribution from this when dealing with cobalt(III) complexes as oxidants, since their reduction to cobalt(II) is, except in the special case of encapsulating ligands, irreversible. One popular way to avoid such problems is to work with symmetrical mixed valence complexes of the bisruthenium(5+) and bisferrocenium(1+) type. For most of these species, intramolecular electron transfer is fast, corresponding to near-infrared frequencies. It is thus a relatively straightforward matter to obtain the appropriate frequency. Two aspects of the spectra need to be checked before attempting to derive kinetic information. The first is to take the obvious precaution of checking that the band in question is indeed intervalence (metal-metal) charge-transfer (IVCT; MMCT) and not simply an MLCT band. The second is to check that the binuclear complex is Robin and Day (ref. 58) Class II in 
character - in other words that the electron really is in transit and not simply stationary in a multicentre orbital encompassing both metals. Here the solvent plays the key role, for the Class I/II/III distinction is made through the solvatochromic characteristics of the MMCT band. Once this criterion has been satisfied, then it is possible to derive an electron transfer rate constant by a somewhat hazardous route (ref. 59) involving the assumption that $\Delta E=\Delta H$ (reasonable, as $p V$ work should be negligible) and that $\Delta G=\Delta H$ (tolerable for symmetrical complexes since solvation effects should cancel) (ref. 60). But of course this approach completely precludes any further discussion of solvent effects on reactivity! Solvent effects on intramolecular electron transfer rate constants can only be assessed for the rare symmetrical systems where kinetic information can be obtained directly, for example by e.s.r. or Mössbauer line-broadening.

\section{ELECTRON TRANSFER: OUTER-SPHERE}

There seems to be rather little information on micellar effects on inner-sphere electron transfer processes, but such effects have been extensively described for their outersphere analogues (refs. 2,61). Here it is possible to study numerous permutations of anionic, cationic, and uncharged reactants and surfactants, with the important additional variable of the hydrophilic/hydrophobic nature of the oxidant and reductant. These may be simple metal ions, inorganic complexes, or organic compounds, again in various combinations.

Separation of medium effects into initial state and transition state components has been carried out for a few outer-sphere redox processes, including the hexachloroiridate(IV) oxidation of iodide in a number of binary aqueous mixtures (ref, 62). The derived pattern for methanol-water media is shown in Fig. 6. A particularly attractive feature of this reaction is that it is possible to model the $\left[\operatorname{IrCl}_{6} \ldots I\right]^{3-\neq}$ rather closely with the $\left[\mathrm{IrCl}_{6}\right]^{3-}$ anion. The results here yet again illustrate the importance of pre-association of the reactants in determining solvent effects on reactivity. To minimise this factor

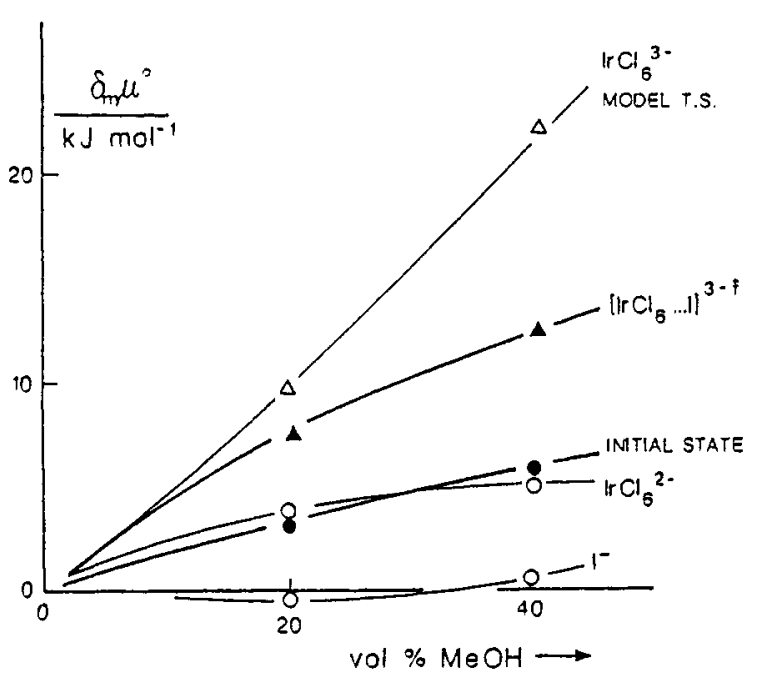

Fig. 6. Initial state - transition state analysis of the $\mathrm{IrCl}_{6}{ }^{2-} / \mathrm{I}^{-}$reaction in water-methanol mixtures (at $298.2 \mathrm{~K}$; $\delta_{m} \mu^{\circ}$ on the molar scale, TPTB assumption).

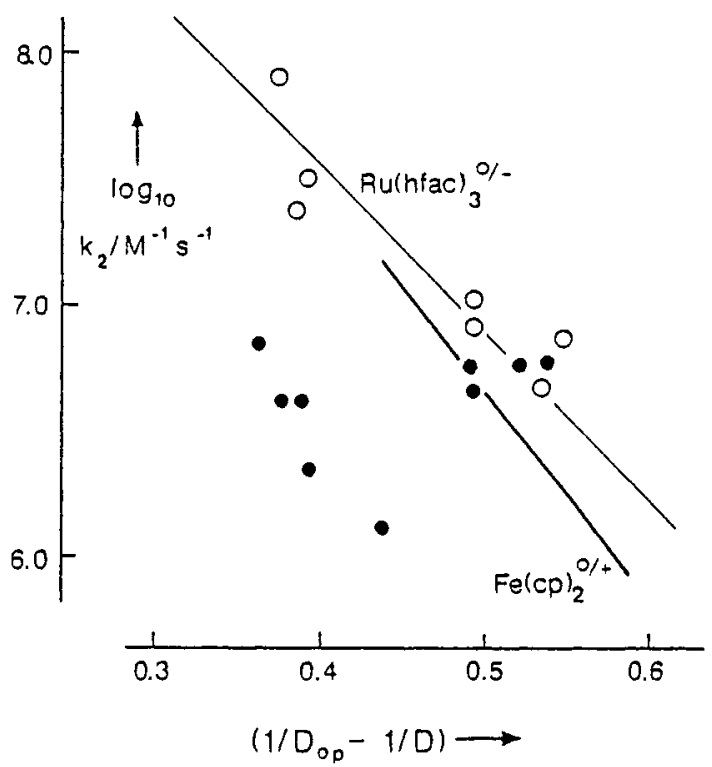

Fig. 7. Dependence of rate constants for electron exchange on the dielectric function $\left(1 / D_{o p}-1 / D\right)$; the lines are those forecast by Marcus theory. 
requires the use of a pair of reactants for which the charge-product $z_{A}{ }_{B}$ is zero, in other words to select a reaction in which one of the reagents is uncharged. This minimises the "work term" in the Marcus equation (ref, 63), enabling one to focus on the actual electron transfer step. The Marcus treatment of solvent effects on electron transfer forecasts a linear dependence of logarithms of electron transfer rate constants on the medium dielectric function $1 / \mathrm{n}^{2}-1 / D$. The $\left[\mathrm{Ru}(\mathrm{hfac})_{3}\right]^{0 /-}$ electron exchange (ref. 64) conforms to this prediction very well, but ferrocene-ferrocinium electron exchange kinetics (ref. 65) emphatically do not (Fig. 7). There is currently much activity in this area in order to resolve this problem (refs. 2,37). The study of electron transfer at electrodes is providing valuable information on the role of solvent relaxation dynamics to complement that obtained from homogeneous solution studies (ref. 66). Most recent studies of medium effects on long-range electron transfer (refs. 66,67) and on very fast electron transfer in the Marcus-inverted region (ref. 68) have dealt with organic substrates, but are now being extended to organometallic (ref. 69), inorganic (ref. 70), and bioinorganic (ref. 71) substrates.

\section{REFERENCES}

1. J. Burgess and E. Pelizzetti, Gazz. Chim. Ital., 118, 803 (1988).

2. J. Burgess and E. Pelizzetti, Prog. React. Kinet., in press.

3. M. Berthelot and L. Péan de Saint-Gilles, Ann. Chim. Phys., Ser.III, 66, 5 (1862) (see pp. 61-67).

4. N. Menschutkin, Z. Phys. Chem., 6, 41 (1890).

5. E. Grunwald and S. Winstein, J. Am. Chem. Soc., 70, 846 (1948); A. H. Fainberg and S. Winstein, J. Am. Chem. Soc., 78, 2770 (1956).

6. R. Huisgen, Accts. Chem. Res., 10, 117 (1977).

7. A. D. English, P. Meakin and J. P. Jesson, J. Am. Chem. Soc., 98, 7590 (1976).

8. J. Burgess, J. Chem. Soc. A, 2114 (1970).

9. J. Burgess, Coll. Surfaces, 48,185 (1990).

10. N. Ise and F. Matsui, J. Am. Chem. Soc., 90, 4242 (1968); J.-R. Cho and H. Morawetz, J. Am. Chem. Soc., 94, 375 (1972).

11. A. W. Zanella and P. C. Ford, Inorg. Chem., 14, 700 (1975).

12. E.g., E. C. Constable, Metals and Ligand Reactivity, Ellis Horwood, Chichester (1990).

13. C. K. Ingold, Structure and Mechanism in Organic Chemistry, Cornell University Press, I thaca, NY (1953).

14. D. A. Brown, A. R. Manning and D. J. Thornhill, Chem. Commun., 338 (1969).

15. M. Herberhold and C. R. Jablonski, Chem. Ber., $1 \overline{02}, 767$ (1969).

16. F. Basolo and R. G. Pearson, Mechanisms of Inorganic Reactions, 2nd.edn., Wiley, New York (1967), chap. 5.

17. M. J. Blandamer, J. Burgess, S. J. Cartwright and M. Dupree, J. Chem. Soc., Dalton Trans., 1158 (1976); M. J. Blandamer, J. Burgess and A. J. Duffield, J. Organomet. Chem., 175, 293 (1979); J. Burgess and A.J. Duffield, J. Organomet. Chem., 177, 435 (1979).

18. C. F. Wells, J. Chem. Soc., Faraday Trans. I, 73, 1851 (1977).

19. C. Tanford, The Hydrophobic Effect, Wiley, New York (1973); J. H. Fendler, Chem.



20. E. Barni and E. Pelizzetti (eds.), Colloids and Surfactants - Fundamentals and Applications, Ann.Chim., 77 (1987).

21. T. F. Tadros, E. Pelizzetti and G. Sironi (eds.), Adv. Coll. Interfac. Sci., 32, 123 (1990).

22. R. Bacaloglu, C. A. Bunton, G. Cerichelli and F. Ortega, J. Phys. Chem., 94,5068 (1990).

23. J. H. van Esch, A. L. H. Stols and R. J. M. Nolte, J. Chem. Soc., Chem. Commun., 1658 (1990).

24. C. Reichardt, Angew. Chem. Internat. Edn., 4, 29 (1965); 18, 98 (1979); Mol. Interactions, 3,241 (1982); Solvents and Solvent Effects in Organic Chemistry, 2nd. edn., VCH, Weinheim (1988).

25. E. Grunwald and S. Winstein, J. Am. Chem. Soc., 70, 846 (1948); S. Winstein, E. Grunwald and H. W. Jones, J. Am. Chem. Soc., 73, 2700 (1951); P. R. Wells, Chem. Rev. , 63, 171 (1963).

26. J. A. Berson, Z. Hamlet and W. A. Mueller, J. Am. Chem. Soc., 84, 297 (1962).

27. M. Gielen and J. Nasielski, Rec. Trav. Chim., 82, 228 (1963); J.organomet.Chem., 1, $173(1964)$.

28. E. M. Kosower, J. Am. Chem. Soc., 80, 3253 (1958); J. Chim. Phys., 61, 230 (1964).

29. K. Dimroth, C. Reichardt, T. Siepmann, and F. Bohlmann, Annalen, $66 \overline{1}, 1$ (1962)

30. V. Gutmann and E. Wychera, Inorg. Nucl. Chem. Lett., 2, 257 (1966); U. Mayer, Pure Appl.Chem., 41, 291 (1975). 
31. U. Mayer, V. Gutmann and W.Gerger, Monatsh., 106, 1235 (1975); U. Mayer, W. Gerger and V. Gutmann, Monatsh., 108, 489 (1977).

32. J.-L. M. Abboud and R. W. Taft, J. Phys. Chem., 83, 412 (1974).

33. M. J. Kamlet, J. L. Abboud and R. W. Taft, J. Am. Chem. Soc., 99, 6027 (1977); M. J. Kamlet, J. L. Abboud, M. H. Abraham and R. W. Taft, J. Org. Chem., 48, 2877 (1983); o. W. Kolling, Analyt. Chem., 56, 430, 2988 (1984).

34. P. Lettelier, R. Gaboriaud and $\bar{R}$. Schaal, Bull. Soc. Chim. Fr., 973 (1972); P. Let telier and R. Gaboriaud, J. Chim. Phys., 70, 941 (1973); R. Gaboriaud, P. Let telier and F. Dorian, J. Chem. Res., (S) $\overline{128, ~(M) ~} 1526$ (1977).

35. S. Brownstein, Can. J. Chem., 38, 1590 (1960).

36. M. J. Kamlet, J. L. Abboud and R. W. Taft, J. Am. Chem. Soc., 99, 6027, 8325 (1977).

37. A. P. Abbott and J. F. Rusling, J. Phys. Chem., 94, 8910 (1990).

38. J. Burgess, J. G. Chambers and R. I. Haines, Transition Met. Chem., 6, 145 (1981).

39. M. J. Blandamer and J. Burgess, Transition Met. Chem., 13, 1 (1988).

40. J. Burgess, R. van Eldik, C. D. Hubbard, M. Patel, S. Radulovic and B. Shraydeh, unpublished work.

41. M. J. Blandamer and J. Burgess, Coord. Chem. Rev., 31, 93 (1980).

42. M. J. Blandamer and J. Burgess, Pure Appl. Chem., 51, 2087 (1979); 54, 2285 (1982); 55,55 (1983).

43. M. Eigen and R. G. Wilkins, Adv. Chem. Ser., 49, 55 (1965); R. G. Wilkins, Accts. Chem. Res. , 3, 408 (1970); Pure Appl. Chem., $\overline{33}, 583$ (1973); Comments Inorg. Chem., 2, 187 (1983).

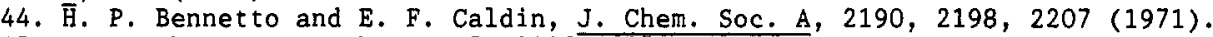

45. M. Tanaka, Inorg. Chem., 15, 2325 (1976).

46. H. S. Golinkin, I. Lee, and J. B. Hyne, J. Am. Chem. Soc., 89, 1307 (1967).

47. E. F. Caldin and M. W. Grant, J. Chem. Soc., Faraday Trans. I, 69, 1648 (1972).

48. E. F. Caldin and B. B. Hasinof $\bar{f}$ J. Chem. Soc., Faraday Trans. I, 71, 515 (1975); B. Hasinoff, Can. J. Chem., 55, 3955 (1977); J. Phys. Chem., 82, 2630 (1978); K. A. Jongeward, D. Magde, D. J. Taube, J. C. Marsters, T. G. Traylor and V. S. Sharma, J. Am. Chem. Soc., 110, 380 (1988).

49. S. Diekmann and J. Frahm, J. Chem. Soc., Faraday Trans. I, 75, 2199 (1979).

50. C. Tondre and M. Boumezioud, J. Phys. Chem., 93, 846 (1989); H. S. Kim and C. Tondre, Langmuir, 5, 395 (1989); and references therein.

51. M. L. Tobe, Inorganic Reaction Mechanisms, Nelson, London (1972), Chapter 9; and see Chapter 6 of reference 16 .

52. E. S. Gould, Accts. Chem. Res., 18, 22 (1985).

53. T. J. Meyer, Ann. N. Y. Acad. Sci., 313, 496 (1978).

54. H. Taube and H. Myers, J. Am. Chem. Soc., 76, 2103 (1954).

55. H. E. Toma, J. Inorg. Nucl. Chem., 37, 785 (1975); J. M. Malin, D. A. Ryan and T. V. O'Halloran, J. Am. Chem. Soc., 100, 2097 (1978).

56. Razak bin Ali, M. J. Blandamer, J. Burgess, P. Guardado and F. Sanchez, Inorg. Chim. Acta, 131, 59 (1987).

57. P. Guardado and R. van Eldik, Inorg. Chem., 29, 3473 (1990).

58. M. B. Robin and P. Day, Adv. Inorg. Chem. Radiochem., 10, 247 (1967); R. J. H. Clark, Chem. Soc. Rev., 13, 219 (1984).

59. T. J. Meyer, Chem. Phys. Lett., 64, 417 (1979).

60. J. T. Hupp and M. J. Weaver, Inorg. Chem., 23, 256 (1984).

61. E. Pelizzetti, Atti Accad. Peloritana, Class. Sci. Fis. Mat. e Nat.(1986, Supp. 2), $64,21(1989)$.

62. M. J. Blandamer, J. Burgess, S. J. Hamshere, C. White, R. I. Haines, and A. McAuley, Can. J. Chem., 61, 1361 (1983).

63. R. A. Marcus, J. Chem. Phys., 24, 966 (1956); Ann. Rev. Phys. Chem., 15, 155 (1964); N. S. Hush, Progr. Inorg. Chem., 8, 391 (1967); $\bar{R}$. A. Marcus and $\mathbf{N}$. Sutin, Biochem. Biophys. Acta, 811, 265 (1985).

64. M.-S. Chan and A. C. Wahl, J. Phys. Chem., 86, 126 (1982).

65. E. S. Yang, M.-S. Chang and A. C. Wahl, J. Phys. Chem., 84, 3094 (1980); R. M. Nielson, G. E. McManis, L. K. Safford and M. J. Weaver, J. Phys. Chem., 93, 2152 (1989); K. Kirchner, S.-Q. Dang, M. Stebler, H. W. Dodgen, S. Wherland and J. P. Hunt, Inorg. Chem., 28, 3604 (1989).

66. M. J. Weaver and G. E. McManis, Accts. Chem. Res., 23, 294 (1990).

67. P. F. Barbara and W. Jarzeba, Accts. Chem. Res., 21, 195 (1988).

68. R. A. Marcus, Disc. Faraday Soc., 29, 21 (1960); J. Phys. Chem., 93, 3078 (1989); J. R. Miller, L. T. Calcaterra and G. L. Closs, J. Am. Chem. Soc., 106, 3047 (1984); J. R. Miller, Nouv. J. Chim., 11, 83 (1987).

69. R. H. Hill, J. Chem. Soc., Chem. Commun., 293 (1989); Pingyun Chen, R. Duesing, G. Tapolsky and T. J. Meyer, J. Am. Chem. Soc., 111, 8305 (1989).

70. T. Guarr, M. McGuire, S. Strauch and G. McLendon, J. Am. Chem. Soc., 105, 616 (1983); T. Ohno, A. Yoshimura, H. Shioyama and N. Mataga, J. Phys. Chem., $91, \frac{1}{4365}$ (1987); P. Neta, R. E. Huie and A. Harriman, J. Phys. Chem., 91, 1606 (1987).

71. K. C. Cho, K. M. Ng, C. L. Uoy, and C. M. Che, Chem. Phys. Lett., 129, 521 (1986); J. L. Karas, C. M. Lieber, and H. B. Gray, J. Am. Chem. Soc., 110, 599 (1988); C. A. Hunter, J. K. M. Sanders, G. S. Beddard, and S. Evans, J. Chem. Soc., Chem. Commun., 1765 (1989); G. Palmer (ed.), Struct. Bonding, 75, (1991). 